\title{
Seasonal variation in the diet of harbour seals in the south-western North Sea
}

\author{
Ailsa J. Hall ${ }^{1, *}$, John Watkins ${ }^{2}$, Philip S. Hammond ${ }^{1}$ \\ ${ }^{1}$ NERC Sea Mammal Research Unit, Gatty Marine Laboratory, School of Environmental and Evolutionary Biology, \\ University of St Andrews, Fife KY16 8LB, United Kingdom \\ ${ }^{2}$ Conservation Research Ltd, 110 Hinton Way, Cambridge CB2 5AL, United Kingdom.
}

\begin{abstract}
Seasonal variation in harbour seal diet in the south-western North Sea was investigated from faeces collected monthly, over a 2 yr period, from a high-water haulout site in the Wash on the east coast of England. A total of 12444 fish otoliths from 31 species was recovered from 708 faeces; otolith measurements were corrected for partial digestion and used to estimate the proportion, by weight, of each species in the diet. Overall, the diet was dominated by whiting $(24 \%)$, sole $(15 \%)$, dragonet $(13 \%)$ and sand goby (11\%). Other flatfish (dab, flounder, plaice: $12 \%$ ), other gadoids (bib, cod: $11 \%$ ), bullrout $(7 \%)$ and sandeels $(3 \%)$ were also consumed. A strong seasonality in diet was apparent which can be summarised as: whiting, bib and bullrout dominated from late autumn through early spring; sand goby peaked during winter and early spring; dragonet, sandeels and flatfish (except sole) dominated from late spring to early autumn; and sole peaked in spring. Harbour seal diet composition in general, and seasonal changes in diet in particular, appeared mainly to be linked to availability (in terms of prey distribution and abundance, feeding or spawning activity and, perhaps, prey sire) but this was not always the case. In a few species (whiting, dab and plaice), seasonal changes in consumption appeared to be related to the availability of other species. Differences in harbour seal and grey seal diets in the same area were consistent with the 2 species feeding in different areas, but there was also evidence of a maximum preferred prey size for harbour seals.
\end{abstract}

KEY WORDS: Faecal sampling · Fish otoliths The Wash Foraging areas - Prey size Prey availability . Predator preference

\section{INTRODUCTION}

The harbour seal Phoca vitulina is a common phocid species whose range spreads across the North Atlantic and North Pacific in temperate and sub-Arctic waters (King 1983). The ease of access to its haulout sites on sheltered coasts, estuaries and inter-tidal sandbanks (Thompson 1989, Riedman 1990) has resulted in this species being much studied throughout its range (Harvey 1987, Bjorge 1991, Wada et al. 1991, HeideJørgensen et al. 1992, Coltman et al. 1997, Iverson et al. 1997, Thompson et al. 1997a, Ries et al. 1998). Many of these studies have examined harbour seal diet (Olesuik et al. 1990, Härkönen \& Heide-Jorgensen 1991, Bowen \& Harrison 1996. Thompson et al. 1996). They

•E-mail: a.hall@smru.st-andrews.ac.uk show that it feeds upon a wide range of prey species which vary from place to place and seasonally. Indeed, recently developed techniques for investigating seal diet, using fatty acid signatures in the blubber that correspond to fatty acid profiles in prey, suggest that harbour seals depend on a very localised prey base (Iverson et al. 1997), a result supported by data on their movements and behaviour.

It has been proposed that observed seasonal and inter-annual changes in the diet of harbour seals are a result of changes in the availability of locally abundant species (Härkönen 1987, Thompson 1989, Pierce et al. 1990). Indeed, it is often stated or inferred that the diet of phocids, including harbour seals, varies seasonally in response to prey availability, but there is limited supporting evidence (Tollit et al. 1997a). Data on seasonal changes in prey distribution, relative abundance and/or behaviour are needed to determine the driving 


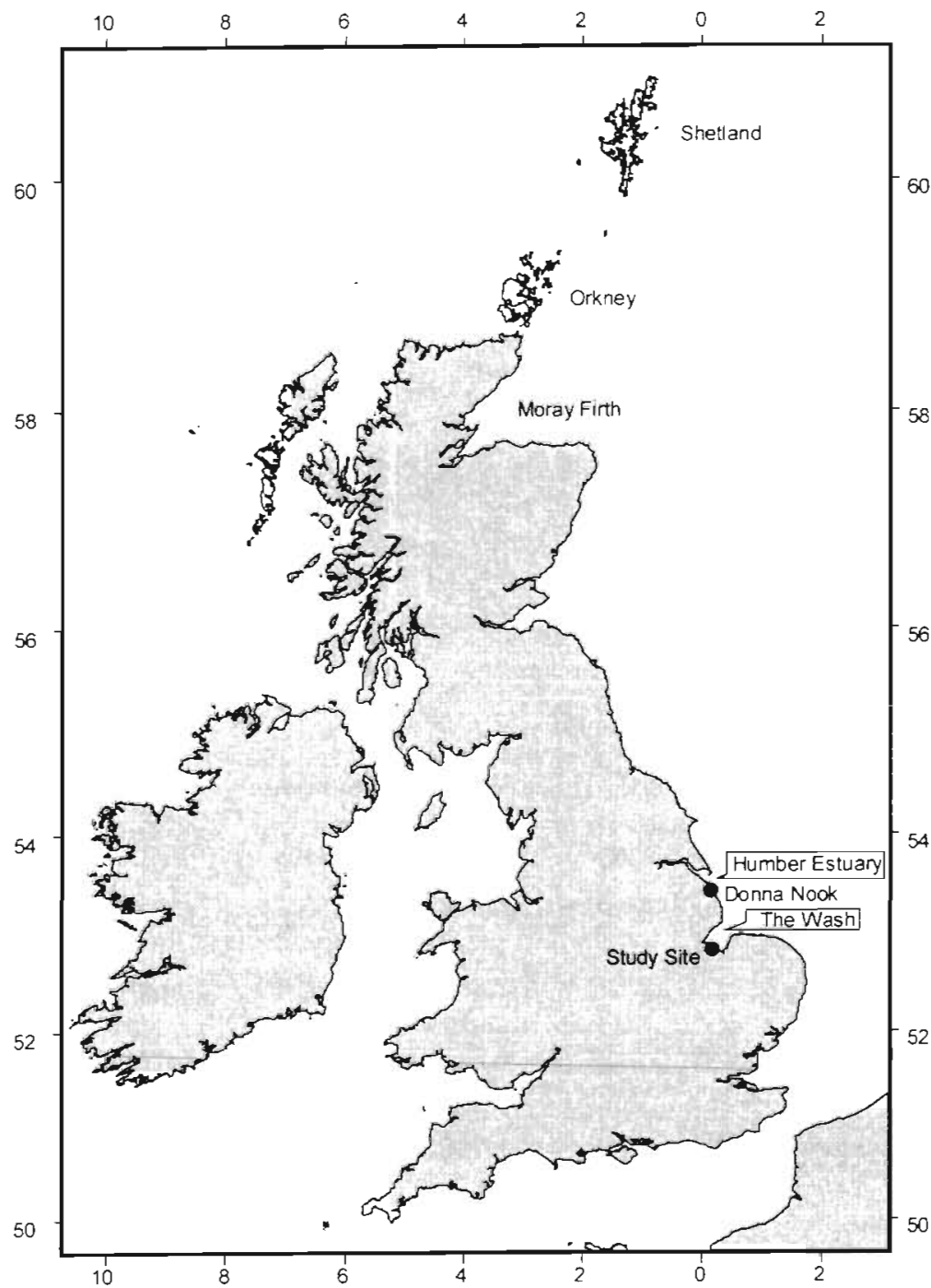

Fig. 1. Map showing the study site in the Wash where harbour seal diet was studied. Also shown are Donna Nonk on the Humber estuary, where grey seal diet has been studied (Prime \& Hammond 1990), and the Moray Firth, Orkney and Shetland, where the other major harbour seal populations ocrur on the east coast of Britain

forces behind seasonal variation in diet. Does the availability of all prey vary seasonally or are some prey taken more in one season because other, preferred prey, become less available at that time? How much is availability influenced by the spatial distribution of prey or by prey size? In this paper we compare the results from a detailed study of harbour seal diet with available data from the literature to explore the evidence that changes in fish distribution, abundance and behaviour in an area of the North Sea influence the diet of harbour seals that haul out in that area

Our field study was conducted in. The Wash, a large area of sand banks and mud flats on the east coast of the North Sea (Fig. 1). The population of harbour seals which hauls out in the Wash is considered to be dis- crete; genetic studies indicate that animals in the Wash are distinct from neighbouring groups which haul out on sand banks in the Dutch Wadden Sea and in the Moray Firth, Scotland (Goodman 1995).

A common method for assessing seal diet involves examining the hard remains of prey recovered from faeces collected from haulout sites (e.g. Hammond et al. $1994 \mathrm{a}, \mathrm{b})$. These prey remains, particularly fish otoliths, can be identified to species and measured allowing estimation of prey size and diet composition (Prime \& Hammond 1987, Pierce et al. 1990). Faecal analysis has been used to examine the diet of harbour seals elsewhere in Europe and Canada (Härkönen 1987, Olesiuk et al. 1990, Pierce et al. 1990, Härkönen \& Heide-Jørgensen 1991, Pierce et al. 1991, Thompson et al. 1991b, Tollit \& Thompson 1996, Brown \& Pierce 1997, Tollit et al. 1997a), facilitating comparisons between studies. The determination of seal diet using the remains of prey recovered from faeces has a number of advantages over other methods and a number of potential biases. These are addressed in the 'Discussion'.

In this paper we present the results of a 2 yr study to investigate the seasonal variation in harbour seal diet in the Wash using analyses of faecal material. Seasonal changes in harbour seal diet composition have also been investigated in other areas and over different time scales (Härkönen 1987, Pierce et al. 1990, Tollit et al. 1997a); we discuss our results, and those from other studies, to explore the evidence for how much these seasonal changes may be caused by changes in prey availability or in predator preference. And we compare our results with those from a study of the diet of grey seals Halichoerus grypus in an adjacent area (Prime \& Hammond 1990) to investigate evidence for separation of foraging niche by area, prey species or prey size.

\section{METHODS}

Data collection. Faeces were collected monthly from a high water haulout site on the south shore of the Wash (Fig. 1), over a 2 yr period between October 1990 and September 1992. Samples were stored individually in plastic bags at $-20^{\circ} \mathrm{C}$. During the first $12 \mathrm{mo}$, a minimum of 30 samples per month was collected. Dur- 
ing the second year, effort was directed towards solid samples, which contain more otoliths, rather than fluid ones, resulting in smaller monthly sample sizes. The consistency and colour of the samples was also recorded. A total of 530 faeces was collected in year 1 (October 1990 to September 1991) and 178 in year 2 (October 1991 to September 1992). Counts of the number of seals hauled out were also made during the study period but sampling typically took place when the haulouts were vacant. Where faeces could be assigned to individual seals from direct observation, size class was confirmed by measurement of the width of track left in the substrate $(>60 \mathrm{~cm}$ adult $<40 \mathrm{~cm}$ juvenile; Reijnders 1976).

Each faex was washed with water through a nest of sieves decreasing in size from 2.0 to $0.355 \mathrm{~mm}$. All otoliths were identified to species (except sandeels, recorded as Ammodytidae). Otolith width, length and thickness were measured with digital callipers to the nearest $0.01 \mathrm{~mm}$, except where the bones were obviously broken or damaged. In faeces where large numbers of otoliths of one species were found, a random sub-sample of 50 was measured. Further details of the faecal processing methods are given in Prime \& Hammond (1987).

Proportion, by weight, of each prey species in the diet. The method of estimating the proportion by weight of each species in the diet comprised: (1) estimating undigested otolith size from partially digested size using experimentally derived species-specific digestion coefficients (Prime \& Hammond 1987, Tollit et al. 1997b); (2) estimating fish weight from estimated undigested otolith size, using species-specific regression relationships (Härkönen 1986); (3) summing the estimated weights for each month to calculate the proportion, by weight, of each species in the diet. Where a sub-sample of otoliths was measured, total weight of that species in a given faex was estimated pro-rata.

Estimation of the variance and confidence limits of the estimated proportions needs to take into account: (1) sampling variation in the estimated weight of fish consumed; (2) various sources of measurement error associated with estimating fish weight from partially digested otolith size.

We used the method of Hammond \& Rothery (1996), which combines resampling from parametric distributions describing measurement error, with bootstrap resampling of the observed data (Efron \& Tibishirani 1993) to estimate the total variance and empirical $95 \%$ confidence limits of estimated proportions of prey species in the diet.

Digestion coefficients and the allometric relationships used to estimate fish weight from undigested otolith size are given in Table 1

Table 1 Digestion coefficients used to estimate undigested otolith size from partially digested otolith size and allometric relationships used to estimate fish weight from undigested otolith size. Fish weight was assumed to be related to undigested otolith size as: $F W=a U^{b} \mathrm{e}^{\sigma^{2} / 2}$, where $F W=$ fish weight, $U=$ undigested otolith size, $a$ and $b$ are constants and $\sigma^{2}=$ variance about the fitted relationship. The multiplier $e^{\sigma^{2} / 2}$ accounts for the estimation error in the predictor variable $U$. To estimate $a, b$ and $\sigma^{2}$, the regression equation: $\ln F W=\ln a+b[\ln U-\operatorname{mean}(\ln U)]+\sigma^{2} / 2$, was used. The mean of $\ln U$ was subtracted from $\ln U$ to balance the regression. Either atolith length $(O L)$ or otolith width $(O W)$ was used as a measure of otolith size, U. (Sources: Härkönen 1986, Coull et al. 1989, Tollit et al. 1997b)

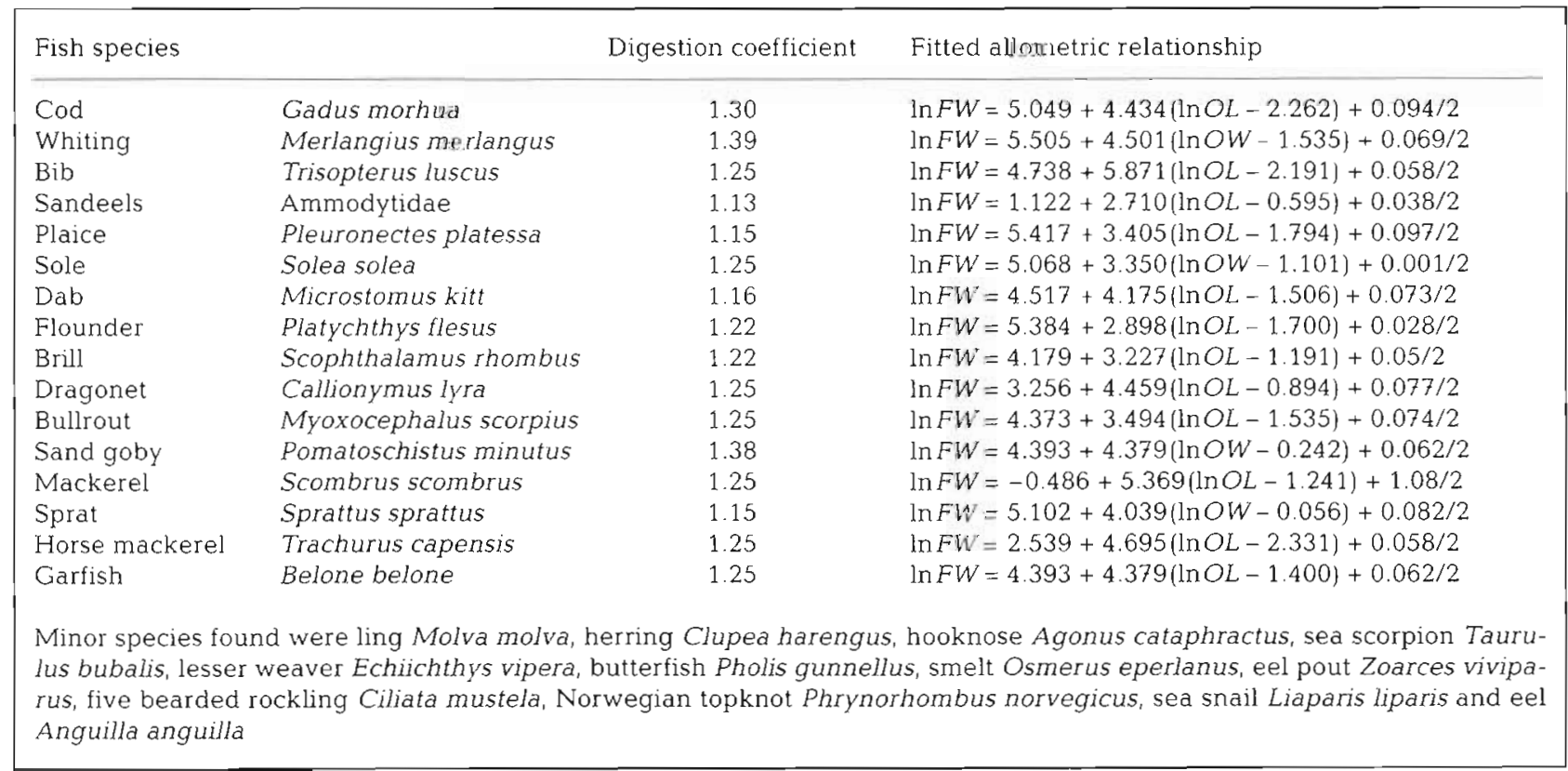


Table 2. Number of samples, and number of otoliths recovered from each of the major prey by trimester Predominant species from the 'Others' category are given un the footnote

\begin{tabular}{|c|c|c|c|c|c|c|c|c|}
\hline \multirow[b]{3}{*}{ No. of faeces: } & \multicolumn{4}{|c|}{ Year 1 - } & \multicolumn{4}{|c|}{$\longrightarrow$ Year 2} \\
\hline & OND & JFM & $A M J$ & JAS & OND & JFM & AMJ & JAS \\
\hline & 111 & 114 & 118 & 187 & 37 & 26 & 44 & 71 \\
\hline & \multicolumn{8}{|c|}{ No. of otoliths } \\
\hline Cod & 37 & - & 7 & 27 & 46 & 13 & 27 & 6 \\
\hline Whiting & 350 & 94 & 65 & 259 & 89 & 46 & 55 & 233 \\
\hline Bib & 79 & 11 & 8 & 19 & 57 & 24 & 5 & 16 \\
\hline Sandeels & 285 & 24 & 218 & 527 & 26 & 19 & 1.00 & 169 \\
\hline Plaice & 34 & 16 & 30 & 292 & 11 & 12 & 11 & 455 \\
\hline Dover sole & 34 & 4 & 44 & 29 & 18 & 19 & 80 & 46 \\
\hline Dab & 149 & 116 & 91 & 761 & 46 & 26 & 1.22 & 281 \\
\hline Flounder & 13 & - & 10 & 62 & - & - & 2 & 25 \\
\hline Brill & - & - & - & 1 & - & - & 3 & 8 \\
\hline Unid, flatfish & 2 & 4 & 14 & 122 & 4 & 3 & 6 & 41 \\
\hline Dragonet & 42 & 3 & 229 & 970 & 15 & 24 & 223 & 348 \\
\hline Bullrout & 52 & 4 & 9 & 12 & 80 & 8 & 16 & 9 \\
\hline Sand goby & 363 & 732 & 407 & 129 & 227 & 870 & 605 & 517 \\
\hline Horse mackerel & 4 & - & - & 6 & 3 & 1 & - & - \\
\hline Sprat & 88 & 34 & 3 & 1 & 15 & 5 & 2 & 1 \\
\hline Mackerel & 4 & - & - & - & - & - & - & - \\
\hline Garfish & 2 & - & 14 & 2 & - & - & 15 & 4 \\
\hline Others & 25 & 15 & $78^{\mathrm{a}}$ & 45 & 38 & 9 & 12 & $138^{\mathrm{b}}$ \\
\hline Total & 1561 & 1057 & 1227 & 3264 & 675 & 1079 & 1284 & 2297 \\
\hline $\begin{array}{l}\text { 55 eel } \\
52 \text { herring }\end{array}$ & & & & & & & & \\
\hline
\end{tabular}

Fish length frequency distributions. To investigate seasonal and annual differences in the size of fish taken by the seals, fish lengths were estimated from the estimated fish weights using published relationships (Bedford et al. 1986).

\section{RESULTS}

\section{Numbers of faeces and otoliths}

The number of faeces collected in each trimester and the number of otoliths recovered for each prey species are shown in Table 2. From a total of 708 faeces, 12444 otoliths were recovered and identified, of which 9019 were measured. Thirty-one fish prey species were identified. The most frequently found otoliths were from cod, whiting, sandeel, plaice, sole, dab, flounder, dragonet, bullrout and sand goby. Some severely eroded flatfish otoliths could not be positively identified but were believed to be either dab or plaice and were apportioned to these species pro-rata. Remains of cephalopod beaks were found in. $12 \%$ of samples overall (a total of 56 beaks in year 1 and 30 beaks in year 2 ). However, they were too small and too eroded to be identified to species and, since they were unlikely to contribute significantly to the diet because of their numbers and size, were excluded for the purposes of estimating diet composition.

\section{Diet composition}

The percentage, by weight (with $95 \%$ confidence intervals), of each of the 12 major species in the Wash harbour seal diet, by trimester, is given in Table 3 There were no major differences between the 2 years of the study. Whiting was the dominant prey species overall $(24 \%)$, with sole $(15 \%)$, dragonet $(13 \%)$ and sand goby $(11 \%)$ other major contributors to the diet. Lesser contributions were made by the flatfish (dab $[6 \%]$, flounder $[4 \%]$ and plaice $[2 \%]]$; the gadoids: (bib $[7 \%]$ and cod $[4 \%])_{i}$ bullrout $(7 \%)$ and sandeels $(3 \%)$.

Seasonal differences were apparent in Table 3 and these appeared to be consistent across years. Threemonth moving averages fitted to the estimated monthly proportions of the major prey species over the 2 years of the study (Fig. 2) show this more clearly. The peaks in proportion by weight in the diet of one species were followed by another through the seasons, over the 2 years of the study. These temporal patterns can be summarised as:

- whiting, bib and bullrout dominated from late autumn through early spring; 
Table 3. Percentage, by weight, and $95 \%$ confidence intervals for the 12 major prey species in the diet of Wash harbour seals

\begin{tabular}{|c|c|c|c|c|c|c|c|c|}
\hline & \multicolumn{7}{|c|}{ Trimester } & \multirow[b]{2}{*}{ JAS } \\
\hline & & OND & & JFM & & $\mathrm{AMJ}$ & & \\
\hline \multicolumn{9}{|l|}{ Year 1} \\
\hline Cod & 6.3 & $(1.4-16.3)$ & 0.0 & - & 1.4 & $(0.1-4.6)$ & 5.0 & $(0.9-14.0\}$ \\
\hline Whiting & 44.0 & $(21.1-70.0)$ & 33.1 & $(6.9-68.7)$ & 12.2 & $(3.5-29.1)$ & 22.1 & $(7.9-44.0)$ \\
\hline Bib & 10.9 & $(0.5-33.5)$ & 14.8 & $(0.3-53.1)$ & 2.9 & $(0.1-14.4)$ & 1.6 & $(0.2-5.3)$ \\
\hline Sandeels & 2.5 & $(0.4-6.5)$ & 1.0 & $(0.1-3.3)$ & 3.6 & $(0.9-8.4)$ & 4.0 & $(1.3-7.9)$ \\
\hline Sole & 5.6 & $(1.3-13.3)$ & 1.8 & $(0.1-5.0)$ & 13.7 & $(4.0-29.6)$ & 3.0 & $(0.8-6.8)$ \\
\hline Plaice & 0.6 & $(0.1-1.6)$ & 0.3 & $(0.0-0.9)$ & 0.4 & $(0.0-1.0)$ & 2.7 & $(0.9-5.3)$ \\
\hline Dab & 4.6 & $(1.4-10.4)$ & 4.0 & $(0.5-12.0)$ & 3.4 & $(0.4-10.0)$ & 10.1 & $(3.9-20.5)$ \\
\hline Flounder & 2.3 & $(0.1-6.4)$ & 0.0 & - & 7.1 & $(0.0-20.7)$ & 7.1 & $(2.7-14.3)$ \\
\hline Dragonet & 2.5 & $(0.4-7.4)$ & 0.2 & $(0.0-1.0)$ & 23.4 & $(5.7-50.5)$ & 37.9 & $(17.2-63.0)$ \\
\hline Bullrout & 9.4 & $(2.4-21.4)$ & 3.6 & $(0.0-14.5)$ & 1.7 & $(0.0-5.2)$ & 1.3 & $(0.0-4.2)$ \\
\hline Sand goby & 5.7 & $(0.7-19.8)$ & 36.7 & $(8.7-76.3)$ & 8.9 & $(0.8-30.0)$ & 2.3 & $(0.4-7.9)$ \\
\hline Sprat & 1.4 & $(0.2-4.1)$ & 2.6 & $(0.4-7.7)$ & $<0.1$ & $(0.0-0.1)$ & $<0.1$ & $(0.0-0.1)$ \\
\hline Others & 4.3 & $(0.4-15.7)$ & 2.0 & $(0.0-7.5)$ & 21.5 & $(1.3-49.3)$ & 3.0 & $(1.1-5.70$ \\
\hline \multicolumn{9}{|l|}{ Year 2} \\
\hline Cod & 5.2 & $(0.8-13.9)$ & 7.3 & $(0.4-23.7)$ & 13.4 & $(1.6-36.5)$ & 1.2 & $(0.0-5.7)$ \\
\hline Whiting & 30.2 & $(8.4-61.5)$ & 25.1 & $(3.8-60.5)$ & 14.0 & $(3.5-33.3)$ & 14.6 & $(4.3-34.1)$ \\
\hline Bib & 21.2 & $(0.9-60.8)$ & 8.3 & $(0.0-28.8)$ & 1.8 & $(0.1-6.6)$ & 1.8 & $(0.0-7.7)$ \\
\hline Sandeels & 0.5 & $(0.0-1.6)$ & 0.6 & $(0.0-2.0)$ & 2.6 & $(0.1-8.0)$ & 3.1 & $(0.8-7.2)$ \\
\hline Sole & 5.2 & $(0.6-14.2)$ & 15.8 & $(2.3-37.7)$ & 23.8 & $(6.0-51.1)$ & 4.0 & $(1.1-9.7)$ \\
\hline Plaice & 0.2 & $(0.0-0.7)$ & 0.2 & $(0.0-0.6)$ & 1.0 & $(0.1-3.5)$ & 9.9 & $(3.6-19.0)$ \\
\hline Dab & 3.8 & $(0.3-10.8)$ & 2.9 & $(0.2-9.2)$ & 5.7 & $(1.7-12.4)$ & 10.7 & $(3.8-21.8)$ \\
\hline Flounder & 0.0 & - & 0.0 & - & 1.1 & $(0.0-4.2)$ & 11.0 & $(2.6-25.4)$ \\
\hline Dragonet & 2.2 & $(0.2-7.6)$ & 4.4 & $(0.0-17.2)$ & 17.2 & $(4.0-38.4)$ & 25.6 & $(8.8-48.8)$ \\
\hline Bullrout & 23.9 & $(6.0-51.0)$ & 5.1 & $(0.5-13.6)$ & 5.6 & $(0.8-13.8)$ & 3.4 & $(0.0-12.1)$ \\
\hline Sand goby & 5.7 & $(0.3-22.7)$ & 27.6 & $(4.4-68.5)$ & 9.4 & $(0.2-34.6)$ & 10.9 & $(2.0-31.4)$ \\
\hline Sprat & 1.0 & $(0.0-4.7)$ & 1.0 & $(0.0-3.8)$ & 0.1 & $(0.0-0.5)$ & 0.1 & $(0.0-0.3)$ \\
\hline Others & 0.8 & $(0.1-2.5)$ & 1.8 & $(0.1-5.2)$ & 4.5 & $(1.1-10.9)$ & 3.7 & $(0.6-10.3)$ \\
\hline
\end{tabular}

- sand goby peaked during winter and early spring;

- sole peaked in spring and again, to a lesser extent, in autumn:

- dragonet, sandeels and flatfish (except sole) dominated from late spring to early autumn.

To determine whether the apparent seasonal changes were real or whether the variability in the estimated proportions was such that the changes with season were not statistically significant, we carried out a series of statistical tests. For each species we selected the trimester (or trimesters) in which the peak proportion by weight in the diet occurred and tested these against the proportions found in the rest of the year. Table 4 shows the results; all comparisons (using a 2-tail $Z$ test) were highly significant ( $p<$ 0.001 ) thus confirming the patterns evident in Table 3 and Fig. 2.

\section{Prey size}

Of the major prey species taken by Wash harbour seals, several were small species. Sand gobies grow only to about $10 \mathrm{~cm}$ in length. Bib, dab, dragonet, bullrout, and lesser sandeels are mostly less than $25 \mathrm{~cm}$ in length, although older individuals and the greater sandeel Hyperoplus lanceolatus may be larger.

Of the larger species, approximately $95 \%$ of the sole taken in both years of the study was less than $35 \mathrm{~cm}$ (Fig. 3). Greater than $90 \%$ of the plaice was less than $18 \mathrm{~cm}$ estimated length in both years (Fig. 3) and greater than $90 \%$ of the cod taken was below $35 \mathrm{~cm}$ estimated length (Fig. 3).

The majority of sandeels taken were in the range 8 to $24 \mathrm{~cm}$ estimated length; this is the size range of the smaller lesser sandeel species Ammodytes marinus and Gymnammodytes semisquamatus or the inshore species A. tobianus. A small number of larger fish up to $32 \mathrm{~cm}$ were found which were probably the greater sandeel (Fig. 3).

A large proportion of the whiting taken were again small fish. More than $90 \%$ were less than $30 \mathrm{~cm}$ estimated length in both years (Fig. 3).

Note that the prey lengths described above have associated error because they are estimated from fish weights which are themselves estimated from measurements of partially digested otoliths. This will tend to 'spread out' the length frequency distributions and means that it is unwise to make inferences from the tails of the distributions. 

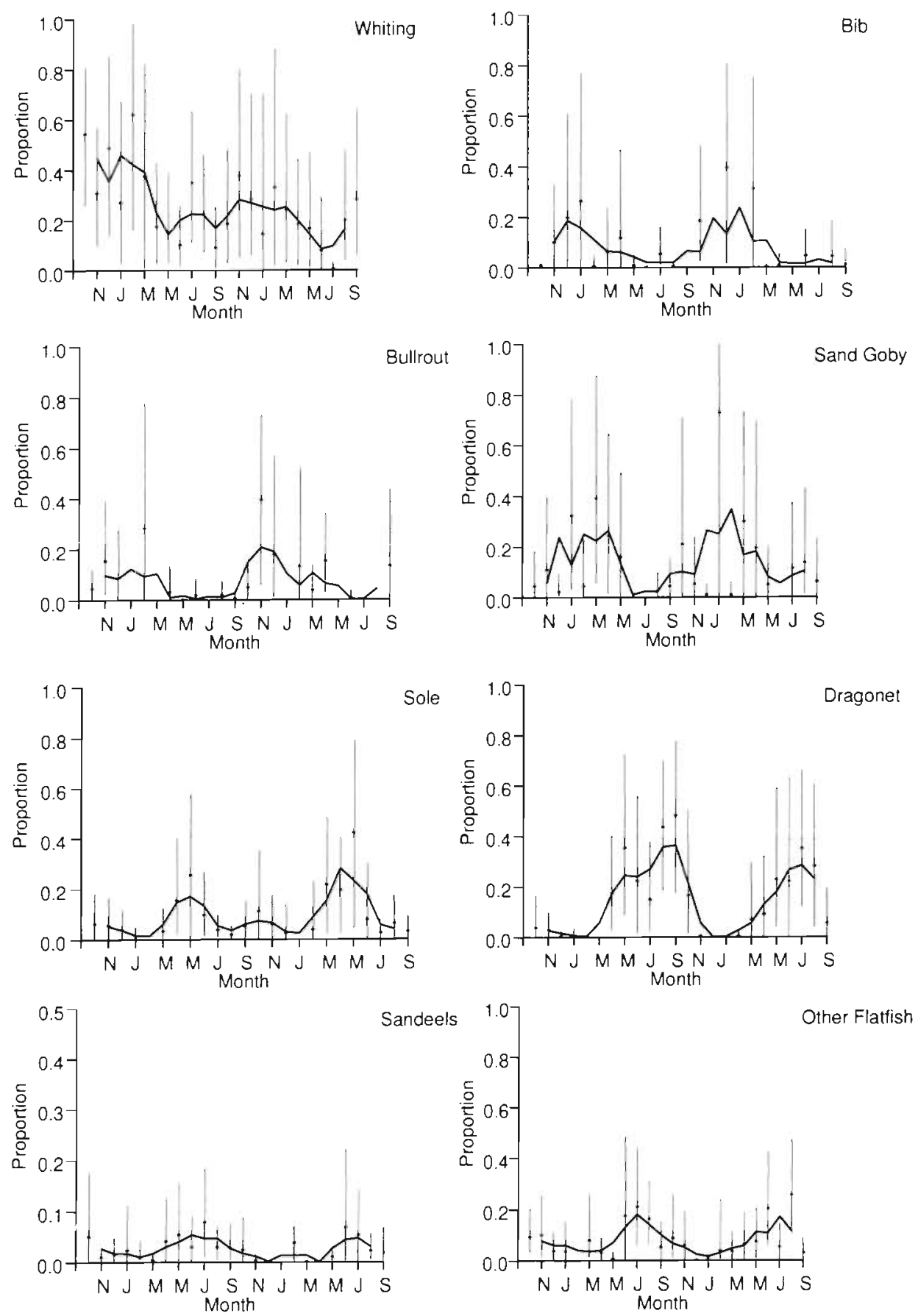

Fig. 2. Monthly proportions, by weight, of the main prey species in the diet of harbour seals in the Wash area The bars around the point estimates are $95 \%$ confidence intervals estimated using the method of Hammond \& Rothery (1996). The solid lines connect threemonth moving averages. $X$-axis key (in order): $N=$ November, $\mathrm{J}=$ January, $M=$ March, $\mathrm{M}=$ Miay, $\mathrm{J}=$ July, $\mathrm{S}=$ September

\section{Other descriptors}

Nematode, acanthacephalan and arachnid parasites, associated with both fish and seals, were frequently found in faecal samples. Many of the nematodes were found in faeces assigned to juveniles and may have been lung worms. They were more prevalent in autumn/winter than spring/summer (the mean proportion of samples containing nematodes between October and April was 0.47 and between May and September was $0.08)$. Faeces from juveniles also tended to be fluid and contained very few otoliths. Of those assigned an age class ( $\mathrm{n}=83$ ), $70 \%$ were from juveniles. Of these, $98 \%$ were fluid and contained a mean of 3.6 otoliths. This would suggest that our results represent the diet of largely adult and sub-adult harbour seals in the Wash. 
Table 4. Seasonal comparisons among major prey species. Trimesters were combined as appropriate. Significance was tested using a 2-tail $Z$ test. Sample sizes were numbers of faeces as given in Table 2. All comparisons were highly significant (p < 0.001 )

\begin{tabular}{|c|c|c|c|c|c|}
\hline Species & \multicolumn{2}{|c|}{ Seasons compared } & \multicolumn{2}{|c|}{ Mean percentage in diet (SE) } & $Z$ \\
\hline \multicolumn{6}{|l|}{ Year 1} \\
\hline Whiting & (a) OND/JFM & (b) AMJ/JAS & (a) $39(10)$ & (b) $17(6)$ & 35.4 \\
\hline Bib & (a) OND/JFM & (b) $\mathrm{AMJ} / \mathrm{JAS}$ & (a) 12 (8) & (b) 2 (2) & 22.0 \\
\hline Sandeel & (a) OND/JFM & (b) $\mathrm{AMJ} / \mathrm{JAS}$ & (a) $2(1)$ & (b) 4 (1) & -37.3 \\
\hline Sole & (a) AMJ & (b) All others & (a) $14(7)$ & (b) $3(1)$ & 29.4 \\
\hline Plaice & (a) JAS & (b) All others & (a) $3(1)$ & (b) $0.4(0.2)$ & 35.5 \\
\hline $\mathrm{Dab}$ & (a) JAS & (b) All others & (a) $10(5)$ & (b) $4(2)$ & 24.8 \\
\hline Flounder & (a) $\mathrm{AMJ} / \mathrm{JAS}$ & (b) OND/JFM & (a) $2(2)$ & (b) 5 (2) & -24.8 \\
\hline Dragonet & (a) $\mathrm{AMJ} / J \mathrm{AS}$ & (b) OND/JFM & (a) $1(0.01)$ & (b) 31 (7) & -506.9 \\
\hline Bullrout & (a) OND & (b) All others & (a) 9 (5) & (b) 1 (1) & 32.6 \\
\hline Sand goby & (a) JFM & (b) All others & (a) $37(18)$ & (b) 6 (3) & 34.3 \\
\hline Sprat & (a) OND/JFM & (b) $\mathrm{AMJ} / \mathrm{JAS}$ & (a) 14 (1) & (b) $0.03(0.03)$ & 170.4 \\
\hline \multicolumn{6}{|l|}{ Year 2} \\
\hline Whiting & (a) OND/JFM & (b) AMJ/JAS & (a) $28(10)$ & (b) $14(5)$ & 13.7 \\
\hline Bib & (a) OND/JFM & (b) AMJ/JAS & (a) $15(10)$ & (b) 2 (2) & 14.2 \\
\hline Sandeel & (a) OND/JFM & (b) AMJ/JAS & (a) $0.5(0.4)$ & (b) 3 (1) & -63.4 \\
\hline Sole & (a) JFM/AMJ & (b) JAS/OND & (a) 5 (2) & (b) 20 (8) & -72.5 \\
\hline Plaice & (a) JAS & (b) All others & (a) $10(4)$ & (b) $0.5(0.3)$ & 24.3 \\
\hline Dab & (a) JAS & (b) All others & (a) 11 (5) & (b) 4 (2) & 14.6 \\
\hline Flounder & (a) JAS & (b) All others & (a) 11 (6) & (b) 1 (1) & 17.5 \\
\hline Dragonet & (a) AMJ/JAS & (b) OND/JFM & (a) 21 (7) & (b) 31 (7) & -10.3 \\
\hline Bullrout & (a) OND & (b) All others & (a) 24 (12) & (b) $12(5)$ & 11.9 \\
\hline Sand goby & (a) JFM & (b) All others & (a) 28 (17) & (b) 12 (5) & 13.5 \\
\hline Sprat & (a) OND/JFM & (b) AMJ/JAS & (a) 1 (2) & (b) $0.08(0.1)$ & 6.3 \\
\hline
\end{tabular}

Particularly notable was the presence of the parasitic copepod Lernaeocera. Specimens could not be conclusively identified to species (Lyndon pers comm.) but were likely to be one of two species: L. Iusci, whose main hosts are bib, dragonet and sand goby; and $L$. branchialis, whose main host is whiting (Van Damme \& Ollevier 1995). We found negative correlations between the number of Lernaeocera and the number of otoliths of bib and sand goby (Pearson correlation coefficents -0.03 and $-0.03, \mathrm{p}>0.05$ respectively), a nonsignificant positive correlation with whiting (Pearson correlation coefficient $0.33, \mathrm{p}>0.05$ ) but a strong positive correlation with the number of dragonet otoliths (Pearson correlation coefficient $=0.77, p<0.001$ ). From this, we infer that the specimens recovered were $L$. lusci parasitising dragonet.

Shrimp remains were found most often in October to December in both years and also in the spring (May in year 1, March and April in year 2). There was no apparent seasonal trend in the presence of other crustaceans.

Other hard remains of interest included green bones, which are known to be indicative of garfish (Brown pers. comm.) and which were often found in association with garfish otoliths (11 samples contained green bones and garfish otoliths; 3 had green bones without garfish otoliths).

\section{DISCUSSION}

\section{Methodology}

The advantages and disadvantages of the method used in this study to determine seal diet, the analysis of otoliths recovered from faeces collected at haulout sites, have been extensively discussed elsewhere (Jobling \& Breiby 1986, Jobling 1987, Hammond \& Prime 1990, Pierce \& Boyle 1991, Cottrell et al. 1996). The main disadvantages that have been identified are: (1) otolith digestion rates may vary by species; (2) small or fragile otoliths, such as those from salmonids and clupeids, may be completely digested; (3) seals may not consume the heads (and therefore the otoliths) of large prey items; (4) some otoliths recovered from faeces may be from the stomachs of primary seal prey. These factors will lead either to a biased sample or to biased results.

In our study, the first potential problem is taken account of by what we see as the major advantage of this method; it allows diet to be quantified, including accounting for the partial digestion of otoliths (Prime \& Hammond 1987) and estimating the full sampling and 'measurement' error (Hammond \& Rothery 1996).

The other potential problems are more difficult to address. We do not believe that the second problem 

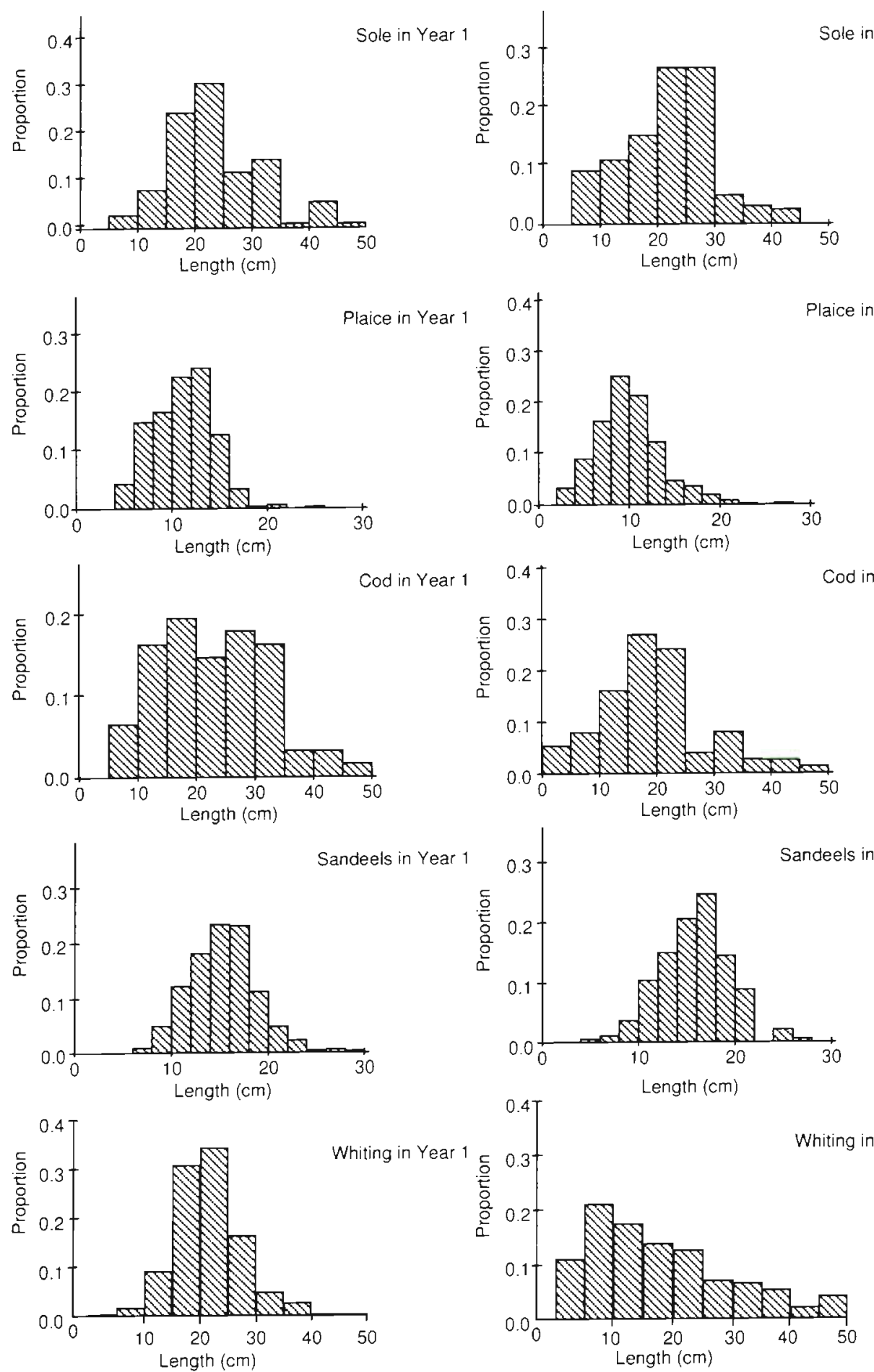

Fig. 3. Length-frequency histograms for 5 major prey species in harbour seal diet in each of the 2 years of the study

could introduce a significant bias into our results. Clupeids and salmonids which have small and fragile otoliths are not abundant in the south-western North Sea and are unlikely to form a significant proportion of harbour seal diet, although sprat were consumed in the winter months. Also, several other studies (referred to below) of harbour seal diet using this methodology have found herring to be a major component of the diet. Regarding the third problem, although there are reports of seals removing the heads of large prey items around fishing nets, there is also much evidence from studies using faecal analysis (again referred to below) that seals do consume large prey because large otoliths are recovered from faeces. 
On the question of whether some otoliths could be from secondary prey, this has been identified as a potential problem with respect to sandeels. In our study, sandeels were a minor prey item so it is unlikely that this is a problem. In other studies where sandeels form a significant part of seal diet (e.g. Hammond \& Prime 1990, Hammond et al. 1994a), it was common to find many hundreds of sandeel otoliths in the absence of otoliths from their predators in individual faeces.

Another important advantage of faecal analysis methods is that it is more efficient than examining stomach contents, either of dead animals (Rae 1968, Rae 1973) or by lavage of live animals (Antonelis et al. 1987), because it is possible to collect large numbers of faeces without disturbing animals. Samples are typically not only larger, but will also be more representative of the population being studied than those taken from animals around fishing nets, for example. We consider the analysis of otoliths recovered from faeces collected at haulout sites as the best overall method for determining the diet of a population of seals.

\section{Harbour seal diet in Europe}

We have presented a detailed assessment of the diet of harbour seals in the Wash area of the North Sea; the first since Sergeant (1951) found mainly common whelks Buccinum undatum, flatfish and whiting in a small sample of stomachs from culled harbour seals. The evidence for common whelks was based mostly on only the opercula and almost certainly these gastropods were secondary rather than primary prey. Our overall results, from a much larger sample of faeces collected monthly throughout a 2 yr period, partly confirm these historical findings. The dominant species in the diet of harbour seals in the Wash in 1990-1992 were whiting and flatfish but these only accounted for about half the diet by weight. Our results show that harbour seals in the Wash are catholic in their feeding habits and take a wide range of fish species. Dragonet, sand goby and bullrout made up about one third of the diet by weight, and gadoids other than whiting about $12 \%$.

In other parts of the North Sea, the diet of harbour seals has been studied in the Kattegat and Skagerrak (Härkönen 1987, Härkönen \& Heide-Jørgensen 1991), the Moray Firth (Pierce et al. 1990, Pierce et al. 1991, Thompson et al. 1991b, Tollit \& Thompson 1996, Tollit et al. 1997a) in Orkney (Pierce et al. 1990) and in Shetland (Brown \& Pierce 1997).

In a 2 yr study in the Skagerrak and Kattegat, Härkönen (1987) found that gadoids made up $50 \%$ and flatfish over $25 \%$ of the diet of harbour seals by weight. A similar study 10 yr later found a similar domination by gadoids but with herring displacing flatfish as the prey type of secondary importance (Härkönen \& HeideJørgensen 1991).

In the Moray Firth, the diet of harbour seals has been found to be dominated by sandeels or herring and sprat, with octopus and gadoids (mainly whiting) also important (Pierce et al. 1990, Pierce et al. 1991, Thompson et al. 1991b, Tollit \& Thompson 1996, Tollit et al. 1997a). In Orkney, sandeels dominated harbour seal diet, followed by herring and gadoids (Pierce et al. 1990). In Shetland, Brown \& Pierce (1997) found that whiting and other gadoids made up over $60 \%$ of harbour seal diet by weight; sandeels and herring were also important.

Sandeels were not an important prey of harbour seals in the Wash. This is similar to some other areas in the North Sea (Härkönen 1987, Härkönen \& HeideJørgensen 1991) and in Canada (Olesiuk et al. 1990, Bowen \& Harrison 1996). It is, however, in contrast to the Moray Firth, where sandeels dominated the diet in summer and, in some years, in winter (Pierce et al. 1990, Pierce et al. 1991, Tollit \& Thompson 1996, Tollit et al. 1997a). These studies show that harbour seals consume a wide variety of prey (gadoids, sandeels, flatfish, clupeids and cephalopods), the favoured species depending on the area and sometimes the year. And in all the studies lasting more than a few months, seasonal differences in the diet were found.

\section{Seasonal changes in harbour seal diet}

In our study, analysis of monthly data over a 2 yr period has enabled us to show that harbour seal diet in the Wash changed seasonally and that this seasonality was consistent across years. The period over which particular prey predominated varied among species from between 3 and 7 mo. A clear progression of dominant species in the diet of whiting, bib and bullrout in winter, through sand goby and sole in spring, to other flatfish and dragonet in summer was apparent for 2 successive years.

Seasonal variation in harbour seal diet has also been highlighted in the Moray Firth. Pierce et al. (1990) grouped their data into trimesters, a decision supported by the scale of seasonal change seen in our results for some species, particularly the flatfish. Pierce et al. (1991) presented the same data by month but the small sample sizes in several months do not warrant the authors' suggestion of pronounced shifts in diet from month to month. Tollit \& Thompson (1996) grouped samples into summer (May to August) and winter (November to February) to highlight the main seasonal differences. In our study, such a grouping would have captured the gross seasonal changes of most species but would not have adequately captured 
the seasonal variation of sand goby and sole, which peaked in spring (Fig. 2). Pierce et al. (1990) and Pierce et al. (1991) found the dominant prey to be sandeels from April to September, and herring and sprat from October to March. Whiting occurred mainly in January to March. Tollit \& Thompson (1996) found the summer diet to be dominated by sandeels, with octopus additionally important in some years, and evidence of a strong prey preference in winter either for sandeels (supported by whiting) or for clupeids. In Orkney, the diet in the 2 summer trimesters was dominated by sandeels (Pierce et al. 1990).

In the Skagerrak/Kattegat, Härkönen (1987) found cod to be the most important prey species except in summer. Lemon sole and herring were major prey except in October to December. Sandeels were only important in April to June, long-rough dab Hippoglossoides platessoides in July to September and whiting in October to December

The results of these studies show clear evidence of seasonal changes in harbour seal diet. Are these changes driven simply by seasonal changes in availability of all prey species? Or are some prey species taken more in a season because other preferred species become less available at that time? To address these questions, it is necessary to examine the evidence for seasonal changes in prey distribution and abundance, as well as behavioural changes that might affect their availability, in the vicinity of the study area. Data collected at the time of our diet study which would allow direct links to be made are not available. We thus rely on data from the literature to make inferences.

\section{Prey availability and predator preference}

Sole is at the northern limit of its distribution in the North Sea (Rijnsdorp et al. 1992), where juvenile fish stay in nursery areas in shallow waters (Knijn et al. 1993) for up to 2 yr (Rees et al. 1988). Most of the sole eaten by harbour seals in our study were these young fish but the length-frequency data indicate that a significant proportion (about $25 \%$ ) were greater than $30 \mathrm{~cm}$ in length (Fig. 3) and thus likely to be mature (Knijn et al. 1993). The increase in the proportion of sole in the diet coincides with the movement of this species into waters less than $30 \mathrm{~m}$ deep to spawn in the southern North Sea (Rijnsdorp et al. 1992). This implies that consumption of sole by harbour seals in the Wash is influenced by availability in inshore waters.

Whiting is an abundant gadoid in the North Sea, widely distributed throughout the year. Immature whiting predominate along the coast of central England but more mature fish are found further south
(Knijn et al. 1993). There is no evidence of seasonal changes in distribution. Whiting was the most important or second most important prey species in the diet of Wash harbour seals throughout the year except in April to June (Table 3). This is the trimester when sole is the dominant prey; indeed there is a strong negative correlation between the proportions by weight in the diet of whiting and sole (Pearson correlation coefficient $=-0.67$ ). This implies that the lower consumption of whiting in spring is a result of prey switching, rather than being due to a decrease in the availability of whiting.

The dragonet is a benthic fish living in shallow water over sand and mud (Wheeler 1978). In the southern North Sea, growth appears to be restricted to the period May/June to October (Van der Veer et al. 1990). King et al. (1994) found that peak feeding occurred during the warmer months and suggested a summer growing season of April/May to September/October. This pattern coincides exactly with the appearance of significant quantities of dragonet in the diet of harbour seals from the Wash (Table 3, Fig. 2) suggesting that their availability as prey is linked to feeding activity during summer. Also noteworthy was the significant correlation between the occurrence of Lernaeocera in faecal samples and the presence of dragonet otoliths. This parasite can be highly debilitating to its host (Hislop \& Shanks 1980). The presence of Lernaeocera may thus also increase the availability of dragonet to seals as prey, particularly at times when the copepod is more prevalent.

The bib is common in inshore waters (Wheeler 1978), found mainly in the southern tip of the North Sea, mostly in winter (Knijn et al. 1993). Consumption of bib by Wash harbour seals was significant, although highly variable, only in winter (Table 3, Fig. 2), suggesting that predation was related to availability. The variability in the diet may be a result of a patchy distribution, as demonstrated elsewhere (Knijn et al. 1993).

The other flatfishes in the diet, mostly dab, flounder and plaice, were found mainly in summer (Table 3 , Fig. 2). The dab has a wide distribution throughout the North Sea, which does not change seasonally (Knijn et al. 1993). The flounder is also widespread in European waters. It migrates into shallow waters in summer but in winter the adults move offshore to spawning grounds which are mainly on the eastern side of the North Sea (Knijn et al. 1993). Newly metamorphosed plaice seek out sandy and muddy bays where they stay for at least a year; dispersal offshore increases from age 2 onwards as the fish begin to mature (Rijnsdorp 1989). The plaice found in Wash harbour seal diet were generally less than $18 \mathrm{~cm}$ estimated length (Fig. 3), and were therefore probably immature (Rijnsdorp 1989). There is thus evidence for seasonal changes in distrib- 
ution only in the flounder. The seasonal predation on $\mathrm{dab}$ and plaice could result from them becoming more available as incidental prey when flounder are targeted

The highest abundance of bullrout in the North Sea is in the Wash and the German Bight (Heessen \& Daan 1996). Spawning occurs in winter (Wheeler 1978, Knijn et al. 1993), the season when bullrout appeared in harbour seal diet (Table 3, Fig. 2), suggesting that predation may be linked to increased availability during spawning.

Sprat was not a major component of harbour seal diet in the Wash but it was more prevalent in winter than in summer (Table 3). This coincides with the occurrence of winter concentrations of sprat in the southern North Sea in coastal areas including the Wash (Corten 1990).

Although sandeels were not an important prey of harbour seals in the Wash, their occurrence in the diet was strongly seasonal, peaking in summer (Table 3, Fig. 2), when they are believed to be more available than in winter (Macer 1966).

The sand goby is abundant in inshore waters over sandy ground, where it is a primary prey of some bottom-dwelling species which are more abundant in winter, such as bullrout and bib (Wheeler 1978). The sand goby was a significant contributor to the diet of Wash harbour seals, particularly from December to April (Table 3, Fig. 2). Its occurrence in the diet may, therefore, be linked to its availability as prey to other fish. It is possible that some of the otoliths recovered from sand gobies may have been secondary rather than primary prey, although we found no correlation between the presence of sand goby otoliths and those of any of its major predators (cod, whiting, bullrout or bib).

In summary, for the majority of prey species which occurred seasonally in the diet of Wash harbour seals, there is circumstantial evidence linking occurrence to a factor likely to affect their availability (distribution, abundance, spawning, feeding activity). For a few species (whiting, dab and plaice), seasonal changes in consumption cannot be explained by these factors and appear to be related to the availability of other species.

\section{Interspecific differences in seal diet}

Prime \& Hammond (1990), using similar methods to those employed here, found that of the diet of grey seals hauled out at the mouth of the Humber estuary (approximately $75 \mathrm{~km}$ from the Wash study site) was dominated by sandeels (except in April/May and November/December), cod (especially in October) and sole (especially in May). Other flatfish, whiting, dragonet and bullrout were also common prey. The range of prey species taken by these adjacent populations of grey and harbour seals was similar (albeit in different years, 1985 and 1990-1992, respectively). There are also similarities in seasonal patterns: the peak in sole consumption in spring; the increase in other flatfish, sandeels and dragonet in summer; and the absence of bullrout and Trisopterus spp. (bib or poor cod) in summer.

But there are more differences than similarities. The main differences are the dominance of sandeels and cod in Humber grey seal diet but the dominance of whiting and certain coastal species (dragonet, sand goby) in Wash harbour seal diet. An additional point of note is that although Wash harbour seals did take advantage of an increase in sole during the spawning season in April/May, as grey seals in the Humber estuary did (Prime \& Hammond 1990), they did not take similar advantage of cod in October (as the grey seals did). Was this because adult cod are too large to be easily consumed by harbour seals? Or was it because the spawning cod did not enter the preferred foraging areas of Wash harbour seals?

In principle, the foraging areas of grey and harbour seals in the southern North Sea could overlap considerably. Harbour seals are known to travel tens of kilometres to feed (Thompson \& Miller 1990, Thompson et al. 1991b, Thompson et al. 1996) whereas grey seals may travel far greater distances (Thompson et al. 1991a, McConnell et al. 1992, Hammond et al. 1993, Thompson et al. 1996, McConnell et al. unpubl.). Prime \& Hammond (1990) suggested that the presence of large sandeels in the diet of Humber grey seals was indicative of offshore feeding on the greater sandeel on the Norfolk and Dogger Banks. Densities of the most abundant sandeel species in the North Sea (Ammodytes marinus) are far greater on the Norfolk Banks than in surrounding deeper waters (Macer 1966). The banks are approximately $100 \mathrm{~km}$ from our harbour seal study site in the Wash, a much greater distance than this species travels to forage in the Moray Firth (Thompson \& Miller 1990, Thompson et al. 1996). We propose, therefore, that the dominance of sandeels in Humber grey seal diet and the low proportions in Wash harbour seal diet is a result of differential foraging in offshore and coastal waters, respectively.

That Wash harbour seals forage coastally is supported by 2 of the dominant prey in the diet: dragonet and sand gobies which, as discussed above, are typically concentrated in coastal waters. Sand gobies were the dominant species in Wash harbour seal diet in January to March. Dragonet was the dominant species in April to June (second to sole in year 2) and July to September.

Whilst almost all the fish taken by Wash harbour seals were small $(<30 \mathrm{~cm}$ in estimated length), includ- 
ing individuals of larger species such as cod and sole, this was not true of Humber grey seals. Prime \& Hammond (1990) found that a wide size range of cod was taken by Humber grey seals; more small fish $(<15 \mathrm{~cm})$ were taken in winter/spring, when they are inshore, but larger fish $(>35 \mathrm{~cm}$ ) were taken throughout the year. Similarly, small sole (5 to $15 \mathrm{~cm}$ ) were taken from December to March but larger fish were also taken throughout the year. In particular, sole $>35 \mathrm{~cm}$ were taken mainly during March to July, the spawning season.

The lack of a seasonal pattern in cod consumption by Wash harbour seals and the small size of fish taken could imply that these fish were in inshore waters, but is also consistent with a maximum limit on the preferred size of prey taken by harbour seals. The failure of Wash harbour seals to capitalise on the larger sole, which are available to Humber grey seals in May, may simply be because these fish are too large.

In conclusion, our study supports the view that harbour seal diet composition in general, and seasonal changes in diet in particular, can mainly be attributed to availability (in terms of prey distribution and abundance, feeding or spawning activity and, perhaps, prey size), but that this is not always the case. This is a comparable result to that found by Tollit et al. (1997a), who reported that whilst the most abundant fish species contributed most to the diet of harbour seals in the Moray Firth, the contribution of the remaining prey species were not correlated to their relative abundance. Härkönen (1987) also noted that while harbour seals in the Skagerrak/Kattegat area took the most abundant gadoid species, they did not feed on several other species of fish that were abundant in the area. Energy requirements may also determine prey selection when a choice exists, for example, species with higher calorific densities might be taken preferentially following periods of fasting. However, nutritional quality and diet composition may also be important. Thompson et al. (1997b) reported that in years when harbour seal diet in the Moray Firth was dominated by gadoids and cephalopods, health and body condition indices in adults and yearlings were significantly lower, compared to years when clupeids were the most important prey species. These nutritional requirements may also be important factors affecting prey selection and foraging in harbour seals.

\section{LITERATURE CITED}

Antonelis GA, Lowry MS, Demaster DP. Fiscus CH (1987) Assessing northern elephant seal feeding habits by stomach lavage. Mar Mam Sci 3:308-322

Bedford BC, Woolner LE, Jones BW (1986) Length-weight relationships for commercial fish species and conversion factors for various presentations. Fisheries Research Data Report No. 10. Fisheries Laboratory, Lowestoft

Bjørge A (1991) Status of the harbour seal (Phoca vitulina L.) in Norway. Biol Conserv 58:229-238

Bowen WD, Harrison GD (1996) Comparison of harbor seal diets in two inshore habitats of Atlantic Canada. Can J Zool 74:125-135

Brown EG, Pierce GJ (1997) Diet of harbor seals at Mousa, Shetland, during the third quarter of 1994. J Mar Biol Assoc UK 77:539-555

Coltman DW, Bowen WD, Boness DJ, Iverson SJ (1997) Balancing foraging and reproduction in the male harbour seal, an aquatically mating pinniped. Anim Behav 54 $663-678$

Corten A (1990) Long-term trends in pelagic fish stocks of the North Sea and adjacent waters and their possible connection to hydrographic changes. Neth J Sea Res 25:227-235

Cottrell PE, Trites AW, Miller EH (1996) Assessing the use of hard parts in faeces to identify harbor seal prey: results of captive feeding trials. Can J Zool 74:875-880

Coull KA, Jermyn AS, Newton AW, Henderson GI, Hall WB (1989) Length/weight relationships for 88 species of fish encountered in the North East Atlantic Scottish Fisheries Research Report No. 43, Department of Agriculture and Fisheries for Scotland, Marine Laboratory Aberdeen

Efron B, Tibshirani RJ (1993) An introduction to the bootstrap. Chapman \& Hall, London

Goodman SJ (1995) Molecular population genetics of the European Harbour Seal (Phoca vitulina) with reference to the 1988 PDV epizootic. PhD thesis, University of Cambridge

Hammond PS, McConnell BJ, Fedak MA (1993) Grey seals off the east coast of Britain: distribution and movements at sea. Symp Zool Soc Lond 66:211-224

Hammond PS, Hall AJ, Prime JH (1994a) The diet of grey seals around Orkney and other island and mainland sites in north-eastern Scotland. J Appl Ecol 31:340-350

Hammond PS, Hall AJ, Prime JH (1994b) The diet of grey seals in the Inner and Outer Hebrides. J Appl Ecol 31 $737-746$

Hammond PS, Prime JH (1990) The diet of British grey seals (Halichoerus grypus). In: Bowen WD (ed) Population biology of sealworm (Pseudoterranova decipiens) in relation to its intermediate and seal hosts. Can Bull Fish Aquat Sci 222:243-254

Hammond PS, Rothery P (1996) Application of computer sampling in the estimation of seal diet. J Appl Statist 23: $525-533$

Härkönen T (1986) Guide to the otoliths of the bony fishes of the north-east Atlantic. Danbiu ApS, Hellerup

Härkonen $T$ (1987) Seasonal and regional variations in the feeding habits of the harbor seals, Phoca vitulina, in the Skaggerak and the Kattegat. J Zool Lond 213:535-543

Härkonen I, Heide-Jorgensen MP (1991) The harbor seal Phoca vitulina as a predator in the Skaggerak. Ophelia 31. $191-207$

Harvey JT (1987) Population dynamics, annual food consumption, movements and dive behaviours of harbor seals (Phoca vitulina richardsi) in Oregon. PhD thesis, Oregon State University

Heessen JL.H, Daan N (1996) Long-term trends in ten non-target North Sea fish species. ICES J Mar Sci 53:1063-1078

Heide-Jorgensen MP, Harkonen T, Dietz R, Thompson PM (1992) Retrospective of the 1988 European seal epizootic. Dis Aquat Org 13:37-62

Hislop JRG, Shanks AM (1980) Recent investigations on the reproductive biology of the haddock (Melanogrammus 
aeglefinus) of the northern North Sea and the effects on fecundity of the copepod parasite Lernaeocera branchialis. J Cons Int Explor Mer 36:244-251

Iverson SJ, Frost KJ, Lowry LF (1997) Fatty acid signatures reveal fine scale structure of foraging and distribution of harbor seals and their prey in Prince William Sound, Alaska. Mar Ecol Prog Ser 151:255-271

Jobling M (1987) Marine mammal faeces samples as indicators of prey importance: a source of error in bioenergetic studies. Sarsia 75:255-260

Jobling M, Breiby A (1986) The use and abuse of fish otoliths in studies of feeding habits of marine piscivores. Sarsia 71. $265-274$

King J (1983) Seals of the world. Oxford University Press, Oxford

King PA, Fives JM, McGrath D (1994) Reproduction, growth and feeding of the dragonet, Callionymus lyra (Teleostei: Callionymidae), in Galway Bay, Ireland. J Mar Biol Assoc UK $74: 513-526$

Knijn RJ, Boon TW, Heessen HJL, Hislop JRG (1993) Atlas of North Sea Fishes ICES Cooperative Research Repart No. 194. ICES, Copenhagen

Macer CT (1966) Sand eels (Ammodytidae) in the south-western North Sea; their biology and fishery Ministry of Agriculture, Fisheries and Food, Fishery Investigation Series $24: 1-55$

McConnell BJ, Chambers C, Nicholas KS, Fedak MA (1992) Satellite tracking of grey seals (Halichoerus grypus). $\mathrm{J}$ Zool Lond 226:27 1-282

Olesiuk PF, Bigg MA, Ellis GM, Crockford SJ, Wigen RJ (1990) An assessment of the feeding habits of harbor seals (Phoca vitulina) in the Strait of Georgia, British Columbia, based on scat analysis. Can Tech Rep Fish Aquat Sci 1730: $1-135$

Pierce GJ, Boyle PR (1991) A review of methods for diet analysis in piscivorous marine mammals. Oceanogr Mar Biol Annu Rev 29:409-486

Pierce GJ, Boyle PR, Thompson PM (1990) Diet selection by seals. In: Barnes M, Gibson RN (eds) Trophic relationships in the marine environment. Proc 24th Eur Mar Biol Symp. Aberdeen University Press, Aberdeen, p 222-238

Pierce GJ, Thompson PM, Miller A, Diack JSW, Miller D, Boyle PR (1991) Seasonal variation in the diet of harbor seals (Phoca vitulina) in the Moray Firth area of Scotland. J Zool Lond 223:641-652

Prime JH, Hammond PS (1987) Quantitative assessment of gray seal diet from fecal analysis. In: Huntley AC. Costa DP, Worthy GAJ, Castellini MA (eds) Approaches to marine mammal energetics. Allen Press, Lawrence, KS, p $161-181$

Prime JH, Hammond PS (1990) The diet of grey seals from the south-western north sea assessed from analyses of hard parts found in faeces. J Appl Ecol 27:435-447

Rae BB $\{1968\}$ The food of seals in Scottish waters. Department of Agriculture and Fisheries for Scotland, Marine Research Report No. 2. HMSO, London

Rae BB (1973) Further observations on the food of seals. J Zool Lond 169:287-297

Rees HL, Riley JD, Franklin A, Green GSJ (1988) Fish and shellfish in the Humber Estuary. In: Edwards AMC (ed) The Humber Estuary: Proceedings of the Conference to Review the Condition of the Ecosystem of the Humber and Tidal Rivers Ouse and Trent in Relation to the Management of Water Quality. Institute of Estuarine and Coastal Studies, University of Hull, p 17

Riedman M (1990) The pinnipeds: seals, seal-lions, and walruses. University of California Press, Berkeley
Reijnders P (1976) The harbour seal (Phoca vitulina) poplution in the Dutch Wadden Sea: size and composition. Neth $J$ Sea Res 10:223-235

Ries EH, Reijnders PJH, Hiby AR (1998) Maximum likelihood population size estimation of harbour seals in the Dutch Wadden Sea based on a mark-recapture experiment. J Appl Ecol 35:332-339

Rijnsdorp AD (1989) Maturation of male and female North Sea plaice (Pleuronectes platessa L.). J Cons Int Explor Mer 46:35-51

Rijnsdorp AD, Van Beek FA, Flatman S, Millner RM, Riley JD, Giret M, De Clerck R (1992) Recruitment of sole stocks, Solea solea (L.) in the Northeast Atlantic. Neth J Sea Res 29: $173-192$

Sergeant DE (1951) The status of the common seal (Phoca vitulina L.) on the east Anglian coast. J Mar Biol Assoc UK 29:707-717

Thompson D, Hammond PS, Nicholas KS, Fedak MA (1991a) Movements, diving and foraging behaviour of grey seals Halichoerus grypus. I Zool Lond 224:223-232

Thompson PM (1989) Seasonal changes in the distribution and composition of common seal (Phoca vitulina) haul-out groups. J Zool Lond 217:281-294

Thompson PM, Miller D (1990) Summer foraging activity and movements of radio-tagged common seals (Phoca vitulina, L.) in the Moray Firth, Scotland. I Appl Ecol 27: 492-501

Thompson PM, Pierce GJ, Hislop JRG, Miller D, Diack JSW (1991b) Winter foraging by common seals (Phoca vitulina) in relation to food availability in the inner Moray Firth, NE Scotland. J Anim Ecol 60:283-294

Thompson PM, McConnell BJ, Tollit DJ, Mackay A, Hunter C, Racey PA (1996) Comparative distribution, movements and diet of harbor and grey seals from the Moray Firth, NE Scotland. J Appl Ecol 33:1572-1584

Thompson PM, Tollit D, Wood D, Corpe HA, Hammond PS, MacKay A (1997a) Estimating harbour seal abundance and status in an estuarine habitat in north-east Scotland. $\mathrm{J}$ Appl Ecol 34:43-52

Thompson PM, Tollit DJ, Corpe HM, Reid RJ, Ross HM (1997b) Changes in haematological parameters in relation to prey switching in a wild population of harbour seals. Funct Ecol 11:743-750

Tollit DJ, Greenstreet SPR, Thompson PM (1997a) Prey selection by harbor seals, Phoca vitulina, in relation to variations in prey abundance. Can J Zool 75:1508-1518

Tollit DJ, Steward MJ, Thompson PM, Pierce GJ, Santos MB, Hughes S (1997b) Species and size differences in the digestion of otoliths and beaks: implications for estimates of pinniped diet composition. Can J Fish Aquat Sci 54: $105-119$

Tollit DJ, Thompson PM (1996) Seasonal and between-year variations in the diet of harbor seals in the Moray Firth, Scotland. Can J Zool 74:1110-1121

Van Damme PA, Ollevier F (1995) Morphological and morphometric study of crustacean parasites within the genus Lernaeocera. Int J Parasitol 25:1401-1411

Van der Veer HW, Creutzberg F, Dapper R, Duineveld GCA, Fonds M, Kuipers BR, Van Noort GJ, Witte JIJ (1990) On the ecology of the dragonet Callionymus Iyra L. in the southern North Sea. Neth J Sea Res 26:139-150

Wada K, Hayama S, Nakaoka T, Uno H (1991) Interactions between Kuril seals and salmon trip net fishery in the coastal waters of southeastern Hokkaido. Mar Mam Sci 7 : $75-84$

Wheeler A (1978) Key to the fishes of northern Europe. Frederick Warne, London 